Brief Communication

COMunicação Breve

Brief COMmunication

\title{
Polemics on Lupoid Sclerosis
}

\section{Polêmicas em Esclerose Lupóide}

\author{
Briele Keiserman $^{(1)}$, Luiz Fernando Garcias da Silva ${ }^{(2)}$, Mauro W. Keiserman ${ }^{(3)}$, \\ Carlos Alberto von Mühlen ${ }^{(3)}$, Henrique Luiz Staub(3)
}

\begin{abstract}
Lupoid sclerosis (LS) is a polemic entity. LS comprises features of both systemic lupus erythematosus (SLE) and multiple sclerosis (MS). Diagnostic criteria are a matter of debate, as well as the role of antinuclear and antiphospholipid antibodies. We here report 5 cases whereby LS could be postulated. Clinical and laboratory findings are discussed, and an updating of the literature on LS is brought about.
\end{abstract}

Keywords: lupoid sclerosis, systemic lupus erythematosus, multiple sclerosis, antiphospholipid antibodies.

Lupoid sclerosis (LS) is an ill-defined entity. The LS spectrum includes features of both multiple sclerosis (MS) and systemic lupus erythematosus (SLE). Antinuclear and antiphospholipid (aPL) antibodies may be detected in such cases. LS seems to comprise one of several neurological entities including focal cerebral and ocular ischaemia, Guillain-Barré syndrome, chorea, seizures, migraine, Dego's disease that are potentially linked to aPL autoantibodies ${ }^{(1)}$. Differential diagnosis of LS could be mostly complex, as herein discussed in 5 case reports.

The first patient, a 34-year-old female, had a history of two episodes of bilateral optic neuritis during the previous 6 years. Five years ago, the patient had acute paraparesia and sphincter incontinence. Magnetic resonance imaging $(\mathrm{MRI})$ revealed demyelinating plaques at the dorsal segment of the spinal cord. Antinuclear antibody (ANA) testing was positive (1/160, nuclear homogeneous). The neurological features ameliorated following treatment with steroids at that time. Few days later, deep vein thrombosis (DVT) of the left lower limb was diagnosed. IgA anticardiolipin (aCL) antibodies were detected in moderate levels.

\section{RESUMO}

A esclerose lupóide é uma entidade polêmica. A afecção engloba achados de ambos: lúpus eritematoso sistêmico e esclerose múltipla. Os critérios diagnósticos são matéria de debate, assim como o papel de anticorpos antinucleares e antifosfolípides. Reportamos aqui cinco casos nos quais o diagnóstico de esclerose lupóide foi postulado. Os achados clínicos e laboratoriais são discutidos, e uma atualização da literatura acerca da esclerose lupóide é efetuada.

Palavras-chaves: esclerose lupóide, lúpus eritematoso sistêmico, esclerose múltipla, anticorpos antifosfolípides.

The patient did not comply with regular anticoagulation. A new episode of optic neuritis was confirmed in the left eye. She recovered after being given steroids. One year prior to this admission, she developed active myelitis, photosensitivity and a new episode of left lower limb DVT; aCL antibodies were absent; ANA testing remained positive (1/640, nuclear homogeneous). Cerebral MRI revealed thickening of the left optic nerve. MRI of the spinal cord showed sparse demyelinating plaques at the cervical and dorsal levels. Cerebrospinal fluid (CSF) analysis was normal. The patient is now stable, receiving montly cyclophosphamide "pulses", low-dose steroids, anticoagulation, and physiotherapy.

The second patient, a 27-year-old female, has complained of cyclical paresthesias of upper and lower limbs for the last 5 years. MRI revealed demyelinating lesions at dorsal cord and cerebral cortex. CSF analysis was unremarkable. ANA and rheumatoid factors were absent. Moderate levels of IgM aCL antibodies were detected in two occasions. Unilateral optic neuritis was diagnosed two years ago and effectively treated with pulsed metyl-prednisolone 
(MP). Mild mitral and tricuspid insufficiency were noticed in the echocardiographic exam. Daily enoxaparin $20 \mathrm{mg}$ subcutaneous combined with aspirin were recently used during pregnancy, whose end-point was successful and uneventful. The patient is now well on low-dose aspirin.

The third patient, a 30-year-old female, showed episodes of optic neuritis for the last 2 years. Recently, thoracic paresthesia developed. ANA testing was weakly positive (1/320, nuclear granular). IgM aCL antibodies were detected in low levels. MRI revealed demyelinating plaques in the dorsal spinal cord. CSF analysis was normal. After 6 monthly cyclophosphamide "pulses" plus steroids, she had a favorable outcome. She remains asymptomatic, receiving low-dose steroids and oral methotrexate.

The fourth patient presented photosensitivity, polyarthralgias, and features of myelitis (paresia of lower limbs, urinary incontinence) 4 years ago. A cerebellar syndrome and bilateral optic neuritis were subsequently diagnosed. Cerebral MRI revealed plaques at the left frontal lobe and right hemisphere. ANA testing was negative. Moderate levels of anti-SSA antibodies and low levels of $\operatorname{IgM} \mathrm{aCL}$ antibodies were detected. The clinical outcome was good after steroid therapy. aCL and anti-SSA antibodies recently cleared. The patient is now well on hydroxichloroquine and physiotherapy.

The fifth patient, a 47-year-old female, has been complaining of arthralgias since she was 33 years-old. A long history of migraine, photosensitivity, xerophtalmia and vitiligo was also present. In 1996, palsy of several cranial nerves was noted. Cerebral MRI and CSF analysis were normal. ANA and aCL antibodies were absent. Mild mitral insufficiency was detected. Steroids and chloroquine therapy were effective at that time. Moderate levels of IgA aCL antibodies and of RF were found in 1997. Neuropathy of median nerves was seen in 1998, when low-dose methotrexate was started. MP "pulse" was carried out in 1998 due to diplopia and refractory migraine. Dry eyes were confirmed in 2001. By February 2002, mild non-erosive synovitis of metacarpo-phalangeal joints was seen. IgM RF test was strongly positive, while IgA aCL antibodies disappeared. In February and October 2004, MP “pulses" were utilized for refractory headache, tetraparesia and bladder dysfunction. The patient is now stable on oral methotrexate and low-dose steroids.

Testing for anti-HIV and anti-HTLV-I/II antibodies resulted negative in all 5 patients.

The nomenclature LS was initially proposed by Stepien \& Cendrowski, in 1974. The authors reported a form of
SLE resembling $\mathrm{MS}^{(2)}$. Two other case reports, in $1977^{(3)}$, and $1984^{(4)}$, accounted for the coexistence of MS and SLE features. Harris et al., in 1985, described a case of a 45year-old woman with transverse myelitis who had a positive IgM aCL antibody test ${ }^{(5)}$. In 1989, Lorcerie et al. reported a patient with a long history of MS who developed laboratory findings suggestive of SLE and APS (ANA, anti-DNA, anti-Sm antibodies, lupus anticoagulant, IgM aCL). Of note, post-mortem examination showed focal demyelination characteristic of MS, but no SLE findings ${ }^{(6)}$.

In 1993, 3 patients fulfilling the diagnostic criteria of both MS and SLE were examined clinically, immunologically and by MRI. Variable cytoimmunological abnormalities were seen in CSF. MRI showed high-signal lesions compatible with MS, but also non-specific small white matter lesions suggestive of small vessel occlusion ${ }^{(7)}$. Simultaneous DVT and transverse myelitis, initially not associated to any autoantibodies, were the first sign of APS, according to a 2006 report $^{(8)}$. Yet more recently, a Brazilian group described a patient previously diagnosed as having MS who later showed livedo reticularis, DVT, ANA and $\mathrm{APA}^{(9)}$.

Transverse myelitis has indeed been seen in primary $\mathrm{APS}^{(10-12)} ; 110$ cases of this association have been reported in the literature ${ }^{(13)}$. Of interest, $73 \%$ of patients who showed transverse myelitis as initial manifestation of SLE or "lupuslike" were aPL-positive ${ }^{(14)}$. These reports (2-14) illustrate the problem of borderline or associations of SLE/APS with MS. The interface of MS, SLE, and APS has been a matter of great interest ${ }^{(15-18)}$. In an analysis of 27 patients, the neurological features of APS and MS were clinically difficult to distinguish. APS patients had significantly increased MRI scores in the putamen as compared to MS patients. If taken individually, nevertheless, MRI from APS patients could not be clearly distinguished from MRI from MS patients. Overall, a history of thrombosis or pregnancy morbitidy, coupled to a favorable response to anticoagulant therapy, might be more reliable in the differential diagnosis ${ }^{(19)}$.

Of interest, anti-myelin antibodies were described in a patient whose features resembled those of LS. Such antibodies were not found in aPL-positive patients with cerebral ischemia ${ }^{(20)}$. A case of acute transverse myelitis similar to LS was reported in a patient with ANA, IgG aCL and antibodies to sulfated glucuronyl lactosaminyl paragloboside (SGLPG) ${ }^{(21)}$.

All our patients showed features of central demyelination. None of them fulfilled classical criteria for $\mathrm{MS}^{(22)}$, however. CSF analysis was uniformly normal. Patient number 1 had typical changes of Devic's neuromyelitis optica 
$(\mathrm{DNO})^{(23)}$. Recurrent DVT associated to (transient) IgA aCL antibodies made primary APS ${ }^{(24)}$ a probable diagnosis. The patient has been maintained on oral anticoagulation. In the second patient, features of DNO were also seen. Given the presence of valve disease and persistent $\operatorname{IgM}$ aCL antibodies, a primary APS could again be claimed. The third patient presented features of DNO and ANA positivity. IgM aCL occurred in low levels. In the fourth case, a "lupus-like" syndrome accompanied a clinical picture of optic and cerebral demyelination. IgM aCL (low titers) and anti-SSA antibodies were transient. In the fifth case, incomplete findings of SLE and Sjögren's syndrome (SS) were noted in a patient with widespread demyelination and transient IgA aCL antibodies.

LS is a difficult-to-prove diagnosis for these 5 patients. Patients 1 to 3 , who showed features of DNO, were all aCL-positive. Moderate aCL titers were seen in two cases, and in one case the antibody was persistently detected. In case 1 , recurrent DVT made continuous anticoagulation a necessity.

The relationship of aPL antibodies with DNO is unclear. A case of DNO associated to SLE and probable APS was recently reported ${ }^{(25)}$. A link of DNO with SLE, in turn, had been originally reported in $1976^{(26)}$. Interestingly, DNO has been described as the first manifestation of $\operatorname{SLE}^{(27)}$. DNO is a polemic entity, being considered as a MS variant. Many patients with DNO do not fulfill the MS criteria. As compared to MS, DNO has a poor prognosis. DNO patients have a higher age at onset, and females are more frequently affected. CSF changes are seen in $65 \%$ of cases, and pleocytosis plus increased proteins are useful in the

\section{REFERENCES}

1. Levine SR, Welch KM: The spectrum of neurologic disease associated with antiphospholipid antibodies. Lupus anticoagulant and anticardiolipin antibodies. Arch Neurol 44: 876-83, 1987.

2. Stepien M, Cendrowski W: Form of systemic lupus erythematosus (lupoid sclerosis) resembling multiple sclerosis. Neurol Neurochir Pol 8: 607-9, 1974.

3. Kaplan PE, Betts HB: Lupoid sclerosis: evaluation and treatment. Arch Phys Med Rehabil 58: 24-8, 1977.

4. Hoppe B, Zajaczek-Grabowska A: Diagnostic difficulties in a case of visceral lupus with disseminated neurological signs. Neurol Neurochir Pol 18: 489-91, 1984.

5. Harris EN, Gharavi AE, Mackworth-Young CG, Patel BM, Derue G, Hughes GRV: Lupoid sclerosis: a possible role for antiphospholipid antibodies. Ann Rheum Dis 44: 281-3, 1985.

6. Lorcerie B, Marchal G, Borsotti JP, et al.: Multiple sclerosis associated with biological symptoms of systemic lupus differential diagnosis with $\mathrm{MS}^{(28)}$. Our three patients with possible DNO had normal CSF, needed to say. An association of DNO with vasculitis has been postulated ${ }^{(29)}$. The neuromyelitis optica IgG antibody (NMO-IgG) has been considerered as an useful marker for $\mathrm{DNO}^{(30)}$. Regarding cases 4 and 5 , central demyelination, despite of being rare, has been a recognized complication of $\mathrm{SLE}^{(31)}$ and $S S^{(32)}$ themselves.

Conceptually, LS is yet to be defined. Whether it represents a distinct entity, an APS variant, or a "demyelinating" SLE/SS subset, is yet to be resolved. Some other questions can be raised:

- Which should be, in fact, the clinical and laboratory criteria for LS? Strict MS and SLE criteria must be fulfilled, or "MS-like/lupus-like" features are sufficient?

- The role of aPL antibodies in the LS pathogenesis is uncertain. They could be transient, as herein shown. Could the newer anti-myelin and anti-SGLPG antibodies be reliable markers for LS? What is the role of CSF markers and MRI for diagnosing this condition?

- Patients with demyelination and persistent aPL antibodies should be treated as having "true" APS?

Are features of SLE/SS/APS found by chance in patients with demyelination?

The literature on LS is still scanty. Further studies, including larger number of patients, might soon clarify concept, classification, and management of this intriguing entity.

erythematosus. A case with anatomical study. Rev Med Interne 10: 471-4. 1989.

7. Kinnunen E, Müllher K, Keto P, Ketonen L, Helve T, Sepponen R: Cerebrospinal fluid and MRI findings in three patients with multiple sclerosis and systemic lupus erythematosus. Acta Neurol Scand 87: 356-60, 1993.

8. Carter D, Olchovski D, Yonath H, Langevitz P, Ezra D: Simultaneous deep vein thrombosis and transverse myelitis with negative sorology as a first sign of antiphospholipid syndrome: a case report and review of the literature. Clin Rheumatol 25: 756-8, 2006.

9. Lima I, Melo A, Brandi IV, Costa O, Santiago M: Lupoid sclerosis: what is the role of antiphospholipid antibodies? J Clin Rheumatol 13: 85-6, 2007.

10. Kim JH, Lee SI, Park SI, Yoo WH: Recurrent transverse myelitis in primary antiphospholipid syndrome - case report and literature review. Rheumatol Int 24: 244-6, 2004. 
11. Takamura Y, Morimoto S, Tanooka A, Yoshikawa J: Transverse myelitis in a patient with primary antiphospholipid syndrome. A case report. No To Shinkei 48: 851-5, 1996.

12. Shaharao V, Bartakke S, Muranjan MN, Bavdekar MS, Bavdekar SB, Udani VP: Recurrent acute transverse myelopathy: association with antiphospholipid antibody syndrome. Indian J Pediatr 71: 559-61, 2004.

13. Téllez-Zenteno JF, Remes-Troche JM, Negrete-Pulido RO, Dávila Maldonado L: Longitudinal myelitis associated with systemic lupus erythematosus: clinical features and magnetic resonance imaging of six cases. Lupus 10: 851-6, 2001.

14. D'Cruz DP, Mellor-Pita S, Joven B, et al.: Transverse myelitis as the first manifestation of systemic lupus erythematosus and lupus-like disease: good functional outcome and relevance of antiphospholipid antibodies. Rheumatol 31: 280-5, 2004.

15. Chapman J: The interface of multiple sclerosis and antiphospholipid antibodies. Thromb Res 114: 477-81, 2004.

16. Ferreira S, D'Cruz DP, Hughes GR: Multiple sclerosis, neuropsychiatric lupus and antiphospholipid syndrome: where do we stand? Rheumatology (Oxford) 44: 434-42, 2005.

17. Suárez Alvarez L, Hughes GR, Khamashta MA: Neurological manifestations of the antiphospholipid syndrome. Med Clin (Barc) 124: 630-3, 2005.

18. Ijdo JW, Conti-Kelly AM, Greco P, et al.: Antiphospholipid antibodies in patients with multiple sclerosis and MS-like illnesses: MS or APS? Lupus 8: 109-15, 1999.

19. Cuadrado MJ, Khamastha MA, Ballesterol A, Godfrey T, Simon MF, Hughes GR: Can neurologic manifestations of Hughes (antiphospholipid) syndrome be distinguished from multiple sclerosis? Analysis of 27 patients and review of the literature. Medicine (Baltimore) 79: 57-68, 2000.

20. Marullo S, Clauvel JP, Intrator L, Danon F, Brouet JC, Oksenhendler E: Lupoid sclerosis with antiphospholipid and antimyelin antibodies. J Rheumatol 20: 747-9, 1993.

21. Inoue $\mathrm{Y}$, Yoshino $\mathrm{H}$ : Acute transverse myelitis presenting with syrinx formation associated with anti-sulfated glucuronyl lactosaminyl paragloboside antibody and anticardiolipin antibodies. No To Shinkei 50: 181-5, 1998.

22. Polman CH, Reingold SC, Edan G, et al.: Diagnostic criteria for multiple sclerosis: 2005 revisions to the "MacDonald Criteria". Ann Neurol 58: 840-6, 2005.

23. Wingerchuck DM, Hogancamp WF, O'Brien PC, Weinshenker BG: The clinical course of neuromyelitis optica (Devic's syndrome). Neurology 53: 1107-14, 1999.

24. Miyakis S, Lockshin MD, Atsumi T, et al.: International consensus statement of an uptade of the classificiation criteria for definite APS. J Thromb Haemost 4: 295-306, 2006.

25. Ferreira S, Marques P, Carneiro E, D'Cruz D, Gama G: Devic's syndrome in systemic lupus erythematosus and probable antiphospholipid syndrome. Rheumatology (Oxford) 44: 693-5, 2005.

26. April RS, Vansonnenberg E: A case of neuromyelitis optica (Devic's syndrome) in systemic lupus erythematosus. Clinicopathologic report an review of the literature. Neurology 26: 1066-70, 1976.

27. Jacobi C, Stingele K, Kretz R, et al.: Neuromyelitis optica (Devic's syndrome) as first manifestation of systemic lupus erythematosus. Lupus 15: 107-9, 2006.

28. Ghezzi A, Bergamaschi R, Martinelli V, et al.: Italian Devic's Study Group (IDESG). Clinical characteristics, course and prognosis of relapsing Devic's Neuromyelitis Optica. J Neurol 251: 47-52, 2004.

29. de Seze J, Stojkovic T, Ferriby D, et al.: Devic's neuromyelitis optica: clinical, laboratory, MRI and outcome profile. J Neurol Sci 197: 57-61, 2002.

30. Scott TF, Kassab SL, Pittock SJ: Neuromyelitis optica IgG status in acute partial transverse myelitis. Arch Neurol 63: 1398-400, 2006.

31. Kovacs JAJ, Urowitz MB, Gladman DD: Dilemmas in neuropsychiatric lupus. Rheum Dis Clin North Am 19: 795-814, 1993.

32. Govoni M, Padovan M, Rizzo N, Trotta F: CNS involvement in primary Sjogren's syndrome: prevalence, clinical aspects, diagnostic assessment and therapeutic approach. CNS Drugs 15: 597-607, 2001 